\title{
Bench berm design using probabilistic key block analysis
}

\author{
E. Hormazabal SRK Consulting (Chile) S.A., Chile
}

\begin{abstract}
In operational open pit mines, large rock surfaces are exposed daily and hundreds or thousands of new discontinuities are exposed, all of which may results in the formation of unstable key blocks and wedges. It is impractical to attempt to map each discontinuity and carry out a stability analysis by the traditional kinematic analysis and wedge/planar failure analysis for each discontinuity mapped. The approach presented in this paper is to design the bench berm configuration in such a manner that sufficient key blocks and wedges will be analysed by probabilistic methods so that an acceptable level of safety is achieved. Geotechnical engineers therefore require a design tool which will allow them to evaluate the type and frequency of key blocks that may be formed and the effect of decreasing the bench angle or increasing the berm width on the probability of failure of the key blocks.

This paper describes a computer program, SBlock in which a probabilistic method is applied to determine the potential key block dimensions, the back break and the berm width for given acceptability criteria. Also, two case histories of operational open pit mines are presented to validate the methodology and calibrate the results.

It is concluded that a probabilistic approach is suitable for the evaluation and design of the bench berm configuration in situations where a large numbers of discontinuities are exposed in the operational open pit benches.
\end{abstract}

\section{$1 \quad$ Introduction}

In operational open pit mines, large rock surfaces are exposed daily and hundreds or thousands of new discontinuities are exposed, all of which may result in the formation of unstable key blocks and wedges. It is impractical to attempt to map each discontinuity and carry out a stability analysis by the traditional kinematic analysis and wedge/planar failure analysis for each discontinuity exposed. The approach presented in this paper is to design the bench berm configuration in such a manner that sufficient key blocks and wedges will be analysed by probabilistic methods so that an acceptable level of safety is achieved. Geotechnical engineers therefore require a design tool which will allow them to evaluate the type and frequency of key blocks that may be formed and the effect of decreasing the bench angle or increasing the berm width on the probability of failure of the key blocks, failure volumes and effective berm widths.

The SBlock program (Esterhuizen, 2004) is a tool that can be used to conduct probabilistic analysis of the effects of discontinuities on bench scale stability. Knowledge of the distribution of the orientation, spacing and length characteristics of discontinuities makes it possible to simulate blocks in the slope face of a bench. SBlock makes use of up to six discontinuity sets to generate blocks that can potentially form along a bench face. Each block is generated independently of previous or following blocks. It is assumed that a block may contain smaller blocks, resulting in large blocks which are limited in size only by the length of the joints. By applying the key block analysis method of Goodman and Shi (1985) each simulated block is evaluated to determine whether it is removable from the surrounding rock mass. Once a key block has been identified, its removability and sliding stability is assessed and accumulated so that the stability of a pit bench can be evaluated. The program reports failure volumes, back break, remaining berm widths and rubble accumulation at the toe of each bench. 
This paper describes how probabilistic bench analysis has been conducted using the SBlock to optimise bench design for given acceptability criteria. Three cases histories of operational open pit mines are presented to validate the methodology and calibrate the results.

\section{$2 \quad$ Method of analysis}

The implementation of the key block method in SBlock allows blocks of any convex shape to be evaluated (Figure 1).Blocks can fail by two-plane sliding or single plane sliding, depending on the shape and location relative to the free face of the bench slope. The key block method is used to identify removability of the blocks. Once removability has been established, the program uses vector methods to determine the sliding direction, normal and shear forces on the sliding planes and the safety factor of the block. Sliding can occur along a single plane (planar failure) or along two planes (wedge failure) and sometimes along three planes (block failure). The user does not have to identify which type of sliding and failure mode to consider - the program identifies blocks and finds whether they can slide out of the face, and the sliding mode.

\section{$2.1 \quad$ The key block method}

Joints and other discontinuities in rock delineate blocks which are enclosed within the rock mass. When an excavation is created, these blocks are exposed in the surface of the excavation. A key block is a block that can displace into an excavation without being obstructed by rock. Key blocks are important from a stability point of view, because they are typically the first blocks to be liberated into the excavation. Such key blocks represent a safety and operational hazard and are of fundamental interest in excavation design.

When designing excavations in jointed rock, it is important to identify the number and size of potential key blocks in the excavation walls. Once key blocks have been identified, it is necessary to establish whether they are likely to be stable, or whether they can slide into the excavation under gravity. Knowledge of the discontinuity orientations and lengths is necessary to identify potential key blocks. The orientation of likely sliding planes and the sliding resistance must be known to conduct a stability analysis of the key blocks. Figure 2 illustrates examples of key blocks that can be formed within a slope face.

The key block method was formalised by Goodman and Shi (1985) who used principles of topology to identify potential key blocks from joint orientations. Blocks are identified that can be infinite or finite. The finite blocks may be removable or not. The removable blocks are further subdivided into stable or unstable blocks depending on the direction of sliding and frictional resistance. The unstable blocks are called key blocks. Once a removable has been identified, vector methods are used to evaluate its sliding stability, or in the case of underground excavations, the potential for the block to be released from the roof. The mathematical basis described by Goodman and Shi for identifying convex removable blocks and evaluating their stability, was used in the development of the SBlock software.

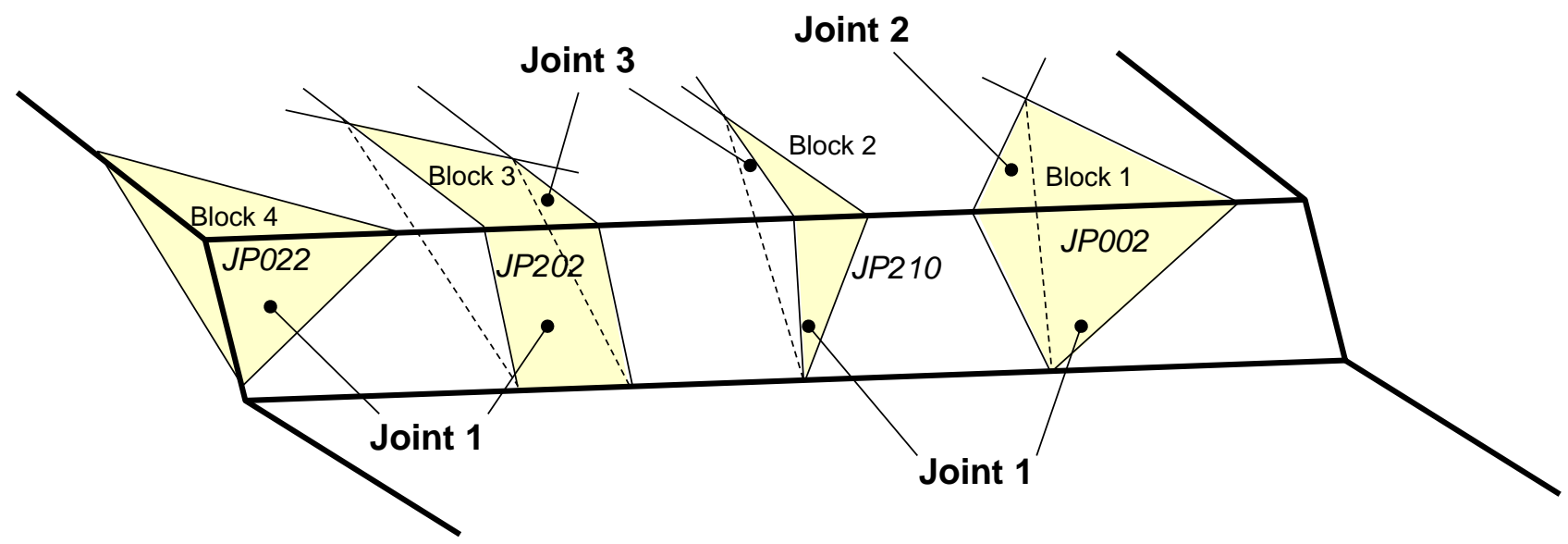

Figure 1 Removable blocks in a rock slope 


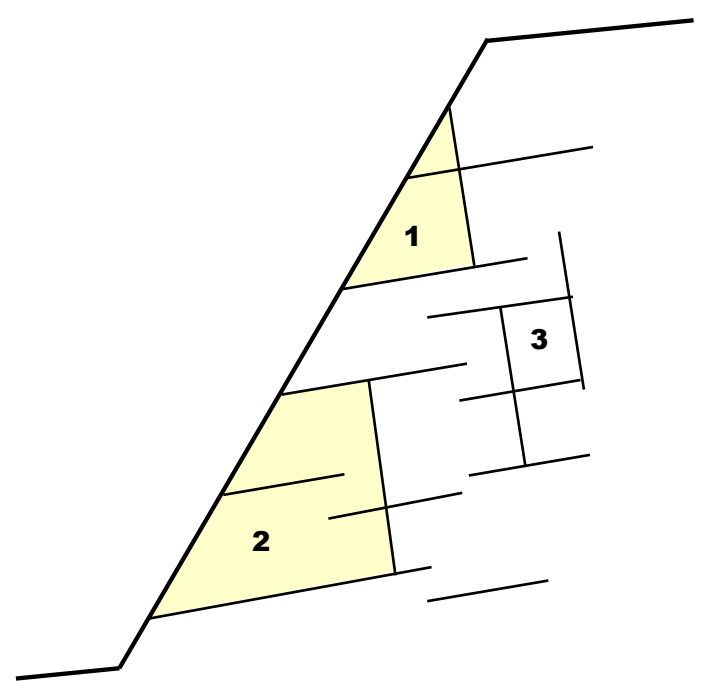

Figure 2 Types of blocks in a slope; (1) key blocks; (2) removable blocks with parallel faces; (3) joint blocks

\subsection{Block formation from joint orientations and trace lengths}

During the development of the SBlock software it was recognised that at an operational site information on discontinuity set orientations, their scatter, the spacing between discontinuities and trace length distributions is likely to be available. Detailed characteristics such as joint area extent or cross-cutting relationships are unlikely to be available. These types of relationships are needed if a full fracture network is to be reconstructed for discrete fracture network modeling (Derschowitz et al., 1996). SBlock only considers a single block at a time and does not attempt to reconstruct the entire interlocked rock mass. It reconstructs one block at a time by replicating the observed trace lengths and orientations, and projecting the discontinuity surfaces back into the rock to determine whether a block is formed. This approach requires that only the distribution of joint orientations, spacing and trace lengths, need to be known to conduct a SBlock analysis. These parameters can be directly observed by standard scan line mapping of excavation surfaces.

In principle SBlock creates one block at a time block by locating joint traces on the surface of the bench slope and determining whether the traces intersect to form a block. Traces are selected based on the apparent frequency of each joint set in the slope surface. Each trace belongs to a joint set and is assigned a random orientation and trace length drawn from the statistics of the set. Joint spacing and trace length is assumed to follow a truncated negative exponential distribution. Joint orientation and strength properties are assumed to follow a normal distribution.

The location and intersections of traces are considered to determine whether a block is outlined on the excavation surface. The potential for cut-off planes to exist, that limit the extent of the block into the rock mass, is tested by considering the location of joint planes along the intersection lines of the traces exposed on the excavation surface. Figure 2 outlines the detailed procedure for identifying a block within the excavation surface and includes the steps that follow to conduct a bench stability analysis.

Once a potential block is identified, an analysis, following the procedures of Goodman and Shi (1985), is conducted to determine whether the block is removable. Removable blocks are further evaluated for stability. If they are unstable, they are counted as key blocks.

\subsection{Block stability}

The stability of a removable block is evaluated by first identifying the sliding direction. The surfaces that are in contact are identified and the distribution of weight onto each surface is determined. A simple Coulomb analysis is conducted to establish whether the shear resistance can resist sliding. Usually the sliding analysis 
is conducted by conservatively assuming frictional resistance only. Single or double plane sliding is automatically identified, based on the orientation of the block relative to the gravity vector.

\subsection{Probabilistic analysis of bench stability}

Knowledge of the stability or instability of a single block is of limited use when thousands are exposed daily in an operating pit. It is only when many thousands of potential blocks are evaluated that their cumulative influence on bench stability becomes apparent.

Bench stability is evaluated by considering a $200 \mathrm{~m}$ long bench. The SBlock software is used to create many thousands of blocks along the $200 \mathrm{~m}$ long bench. A portion of the blocks will be key blocks while many blocks will be non-removable. Blocks are located at random locations in the bench face. Figure 3 demonstrates how a classical wedge-type block might be formed when a six-sided block is randomly located within a bench face.

Blocks may overlap, but the failure volume is only accumulated once if failure occurs. Three horizontal scan lines are simulated near the top, middle and bottom of the bench face and the joint trace intersections with the scan lines are counted. The number of joints intersecting the scan lines is checked against the expected joint frequency along the scan lines. When a sufficient number of joints have been sampled by the scan lines, a new bench will be started.

The failure volume and other statistics are accumulated for each bench, and a summary is provided at the end of each run. Several hundred benches can be sampled to obtain representative statistics of bench stability. Figure 4 shows a view onto a $200 \mathrm{~m}$ bench face showing the outline of blocks - red outlines show unstable blocks and blue ones are stable. It does not show every joint, however, but only joints that form block edges.

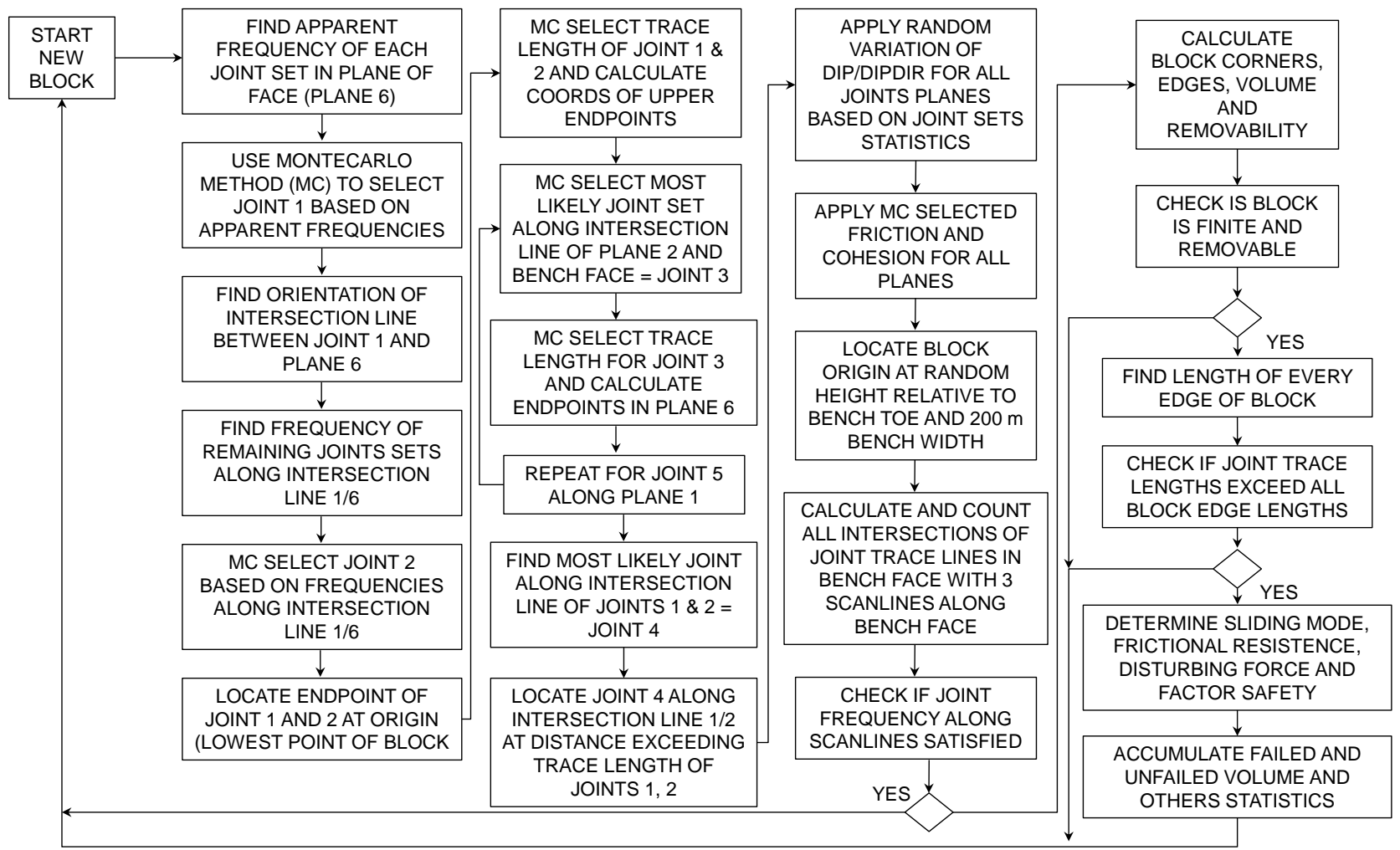

Figure 3 Flowchart for block formation from trace length and orientation statistics 


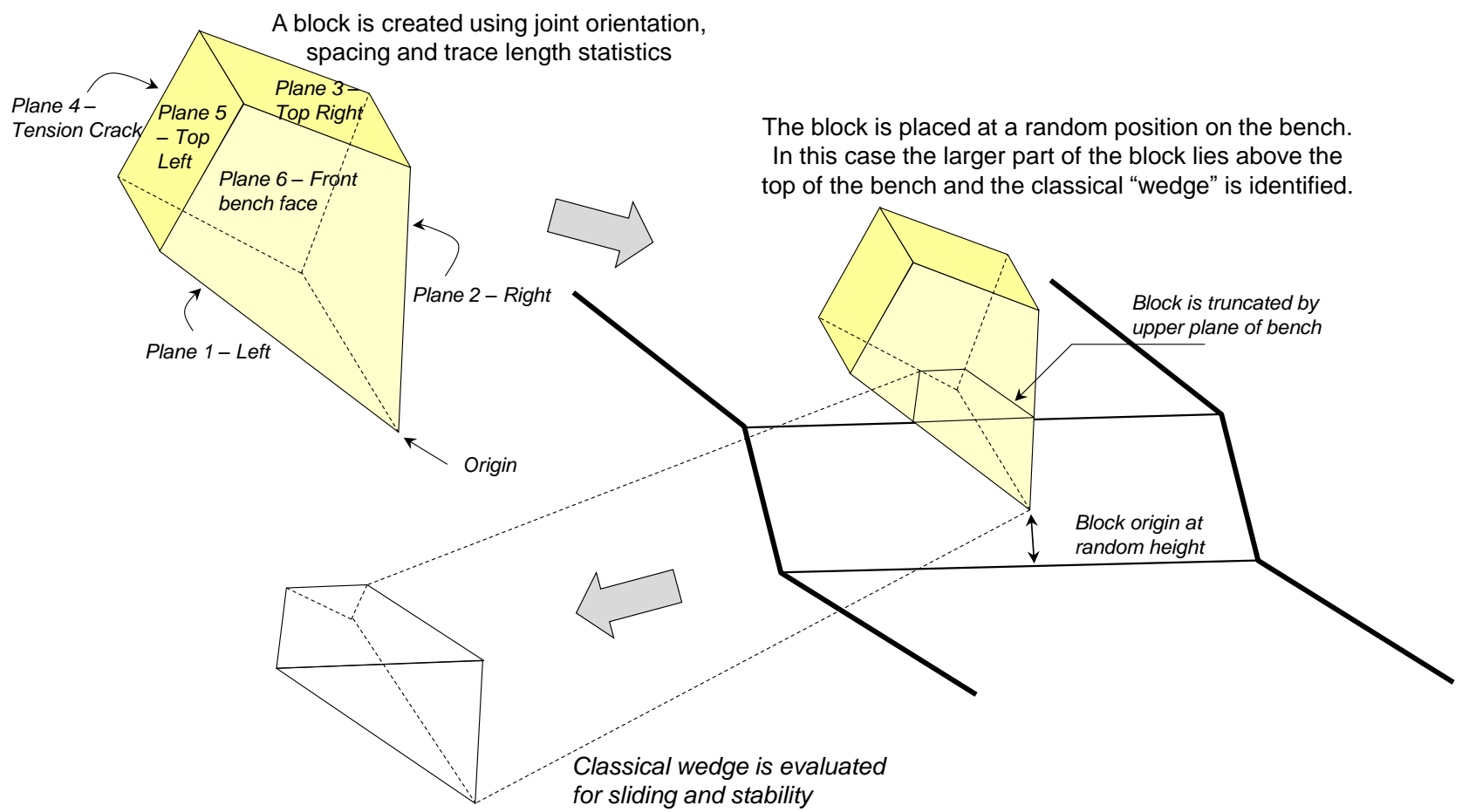

Figure 4 Example showing how a classic wedge shaped block may be formed

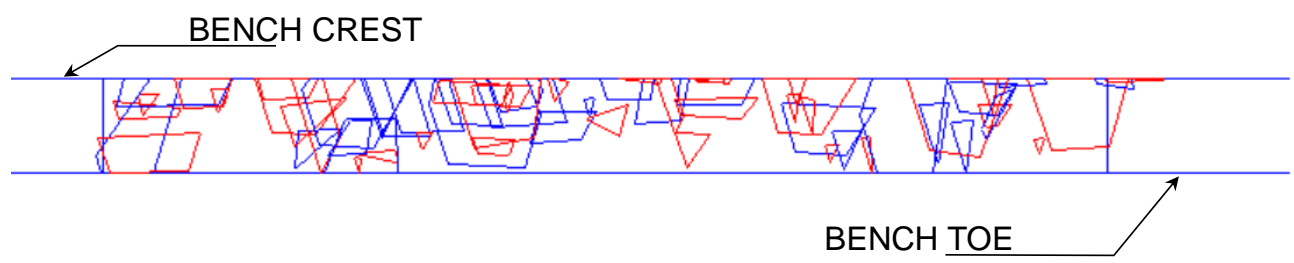

Figure 5 Random locations of blocks along a bench; red blocks are unstable (SBlock output)

\subsection{The SBlock input data set}

The following input parameters need to be included in the analysis:

- Orientation: Joint set orientations are defined by the average dip $\left(0-90^{\circ}\right)$, the dip direction $\left(0-360^{\circ}\right)$ clockwise from north. The Range specifies the scatter of the dip and dip direction in degrees. A scatter of $40^{\circ}$ means the dip and dip direction vary by $20^{\circ}$ above and below the average value.

- Spacing: The average joint set spacing is entered as the mean spacing; the minimum spacing and maximum spacing are required. Program assumes the joint spacings follow a negative exponential distribution, truncated at the minimum and maximum values.

- Length: Joint trace length is considered as the mean length; also the minimum and maximum trace length is considered. Program assumes the joint trace length follows a negative exponential distribution, truncated at the minimum and maximum values.

- Shear strength Properties: The joint set average friction angle and cohesion are needed for the analysis. A simple linear Mohr-Coulomb criterion is used to calculate the resistance to shearing. Joints can be minor faults, bedding, joints or any discontinuity.

- Bench geometry: The data required for the bench geometry is the following: bench face dip; bench face dip direction; bench height and bench width. 


\subsection{Results of the failure analysis}

The following results can obtained from the analysis:

- Average failure volume: Average volume of failed rock calculated by a $1 \mathrm{~m}$ wide slice taken every $2 \mathrm{~m}$ along the strike of the benches simulated. This includes parts of the bench where zero failure occurred. Failure volume is expressed as a volume per $1 \mathrm{~m}$ run along the bench strike.

- Average Factor of Safety of blocks/wedges: A simple average of all Factors of Safety of blocks that can slide towards the free face. This includes stable and unstable blocks but excludes blocks that slide towards the solid rock (that is sliding away from the bench free-face).

- Bench crest failure depth: the depth of failure of the bench crest is expressed as a probability of failure (Figure 6). This figure shows that there is a $53 \%$ probability that the crest will be failed and the probability drops to about $20 \%$ at a depth of $6 \mathrm{~m}$. it also shows the pile of rubble that will form at the toe of the slope - based on the average volume of failure. This shows that the bench effectiveness is reduced by about $95 \%$.

- Average effective bench width: This is the average horizontal dimension of all benches simulated and shows the effect of crest failures on bench width. If the benches were designed to be $15 \mathrm{~m}$ wide and the effective width is $11 \mathrm{~m}$, it means that on average $4 \mathrm{~m}$ of bench crest has fallen away, also known as back break.

- Failure free bench length: Length of bench crest that did not experience any failure expressed as a percentage.

- Average non-zero failure volume: Average failure volume obtained by dividing the total failure volume by the length of crest affected by failure (excludes unaffected crest length from the calculation). This gives a good idea of the amount of failed rock at each failure location. Sometimes only one or two large failures occur and expressed as an average over the entire bench length they may seem small, but each individual failure might be large.

- Average required bench width: The width of bench required holding the average failure volume, based on an angle of repose of $30^{\circ}$ and $40 \%$ swell. It is assumed that the failed rock is in the form of rubble and lies in a pile at the toe of each bench. This gives an indication of how wide the benches should be to hold the failed volume. It should be compared to the effective bench width. The cumulative distribution of berm width is also provided (Figure 7).

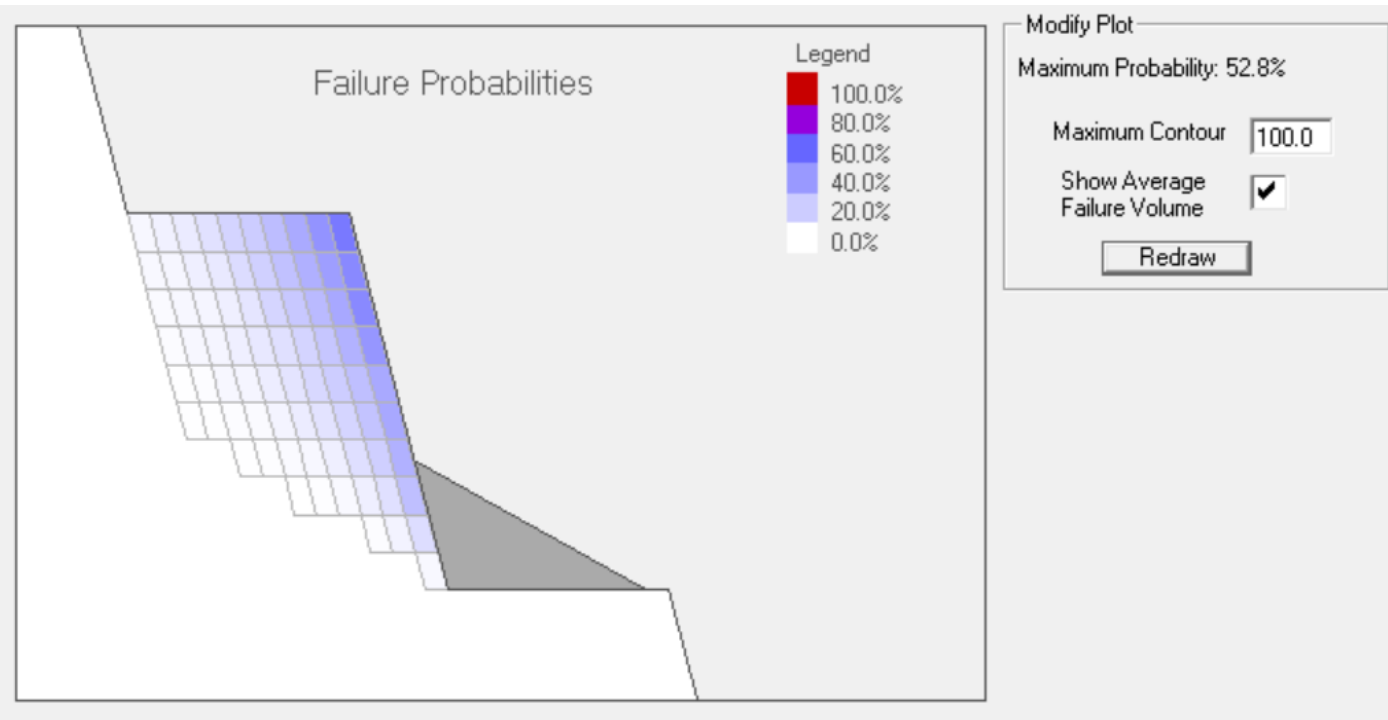

Figure 6 Depth of failure of a bench expressed as a probability of failure (SBlock output) 
Cumulative Distribution of Bench Widths

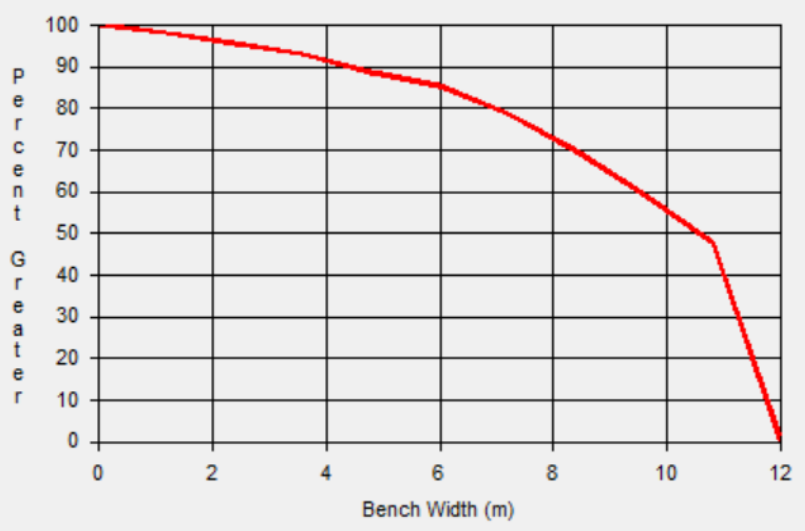

Figure 7 Cumulative distributions of bench widths for berms that were originally $12 \mathrm{~m}$ wide. The figure shows, for example, that $80 \%$ of the benches are greater than $7 \mathrm{~m}$ wide (SBlock output)

\section{$3 \quad$ Examples of application at mining operations}

The SBlock methodology has been applied in several operating mines and projects at different stages of development. Three of those mines have been selected to illustrate the use of the methodology in real case situations.

\subsection{Carmen de Andacollo open pit (Teck)}

The Carmen de Andacollo (CDA) pit is located in central Chile, adjacent to the town of Andacollo, approximately $55 \mathrm{~km}$ southeast of La Serena and $350 \mathrm{~km}$ north of Santiago. The mine is located near the southern limit of the Atacama Desert at an elevation of 1,000 m. CDA is an open pit mine which produces copper in concentrates from the hypogene portion of the orebody. Copper cathode production from the supergene portion of the orebody is currently approaching completion. According to the geotechnical information provided from surface mapping and logging of several campaigns in the past, in the CDA pit seven structural domains had been defined (Hormazabal et al., 2011). Recognised structural features correspond to 1st order regional faults (Carmen, Hermosa, Andacollo and Twila faults), 2nd order faults (NS and N) and 3rd order (NW and lithology contacts). Table 1 summarises the structural parameters for the Southwest sector.

Table 1 Structural data for West Domain

\begin{tabular}{ccccccccc}
\hline \multirow{2}{*}{ Set } & Dip & Dip & \multicolumn{3}{c}{ Spacing $(\mathrm{m})$} & \multicolumn{3}{c}{ Persistence $(\mathrm{m})$} \\
& & Direction & Mean & Min & Max & Mean & Min & Max \\
\hline Joint 1 & $65^{\circ} \pm 20^{\circ}$ & $245^{\circ} \pm 30^{\circ}$ & 10 & 5 & 15 & 30 & 15 & 45 \\
Joint 2 & $72^{\circ} \pm 20^{\circ}$ & $278^{\circ} \pm 30^{\circ}$ & 10 & 5 & 15 & 30 & 15 & 45 \\
Joint 3 & $72^{\circ} \pm 20^{\circ}$ & $313^{\circ} \pm 30^{\circ}$ & 10 & 5 & 15 & 30 & 15 & 45 \\
Joint 4 & $86^{\circ} \pm 20^{\circ}$ & $007^{\circ} \pm 10^{\circ}$ & 5 & 1 & 15 & 10 & 5 & 15 \\
Joint 5 & $86^{\circ} \pm 20^{\circ}$ & $033^{\circ} \pm 10^{\circ}$ & 5 & 1 & 15 & 10 & 5 & 15 \\
Joint 6 & $86^{\circ} \pm 20^{\circ}$ & $214^{\circ} \pm 10^{\circ}$ & 5 & 1 & 15 & 12 & 6 & 18 \\
\hline
\end{tabular}


Notes:

Bench face dip $=70^{\circ}$; bench face dip direction $=240^{\circ}$; bench height $=10 \mathrm{~m}$; bench berm width $=6.0 \mathrm{~m}$.

Friction angle $=20^{\circ}$ and cohesion $=0$, for all joints $/$ planes (discontinuities).

An onsite calibration was carried out using values shown in Table 1 for the different slope orientations in the Southwest domain. A 3D plot of the benches indicates the location of failures identified by the program (Figure 8). This output from the program shows a good visual correlation with the slope benches, and provided realistic estimates of the total failure volume, which helped to validate the methodology. Shear strength properties of faults/joints agreed with back-analyses and direct shear tests.

After the calibration was complete, the methodology was applied for different push-backs in the same structural domain. Figure 9 shows the application to the Southwest sector (final pit). This figure shows the probability of failure expressed as a depth of failure of a bench. The results show that there is a $10 \%$ probability that the crest will fail and the probability drops to about $4 \%$ at a depth of $3.6 \mathrm{~m}$. It also can be note the pile of rubble that will form at the toe of the slope - based on the average volume of failure. The bench effectiveness is reduced by about $40 \%$. This result shows that $90 \%$ of benches can be expected to be greater than $5.5 \mathrm{~m}$ wide. These dimensions and expected failure volumes are considered to be acceptable by the mine operational management.
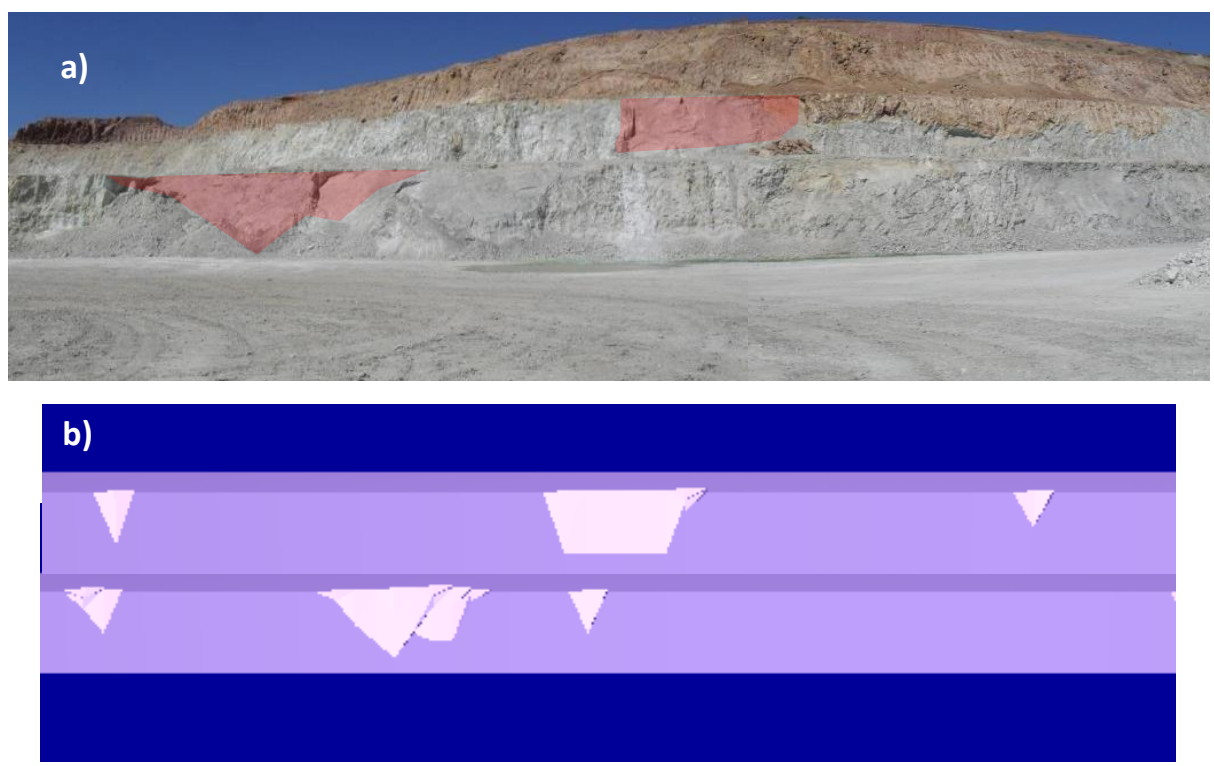

Figure 8 Calibration onsite of bench berm analysis; (a) photograph of the slopes benches in the southwest structural domain; (b) output of SBlock program showing the failed blocks removed (red zones) for this sector using southwest structural domain data shown in Table 1 


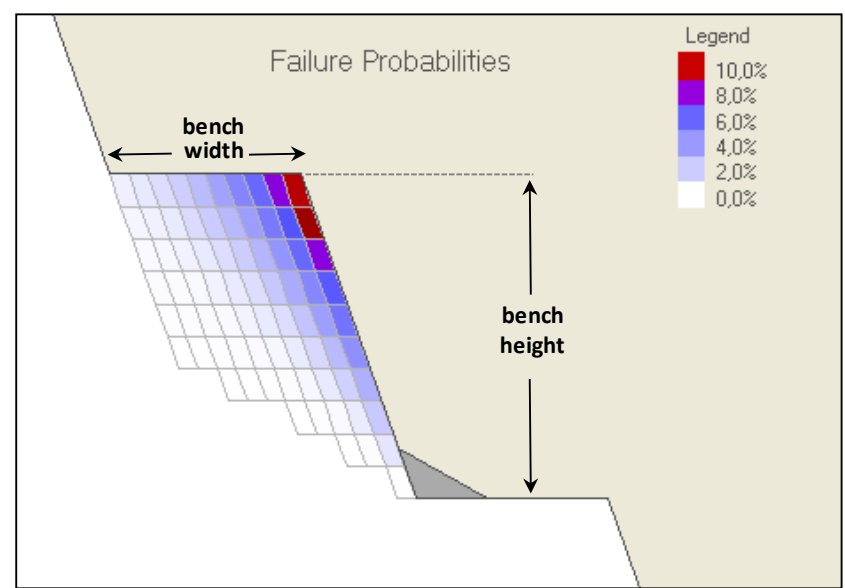

(a)

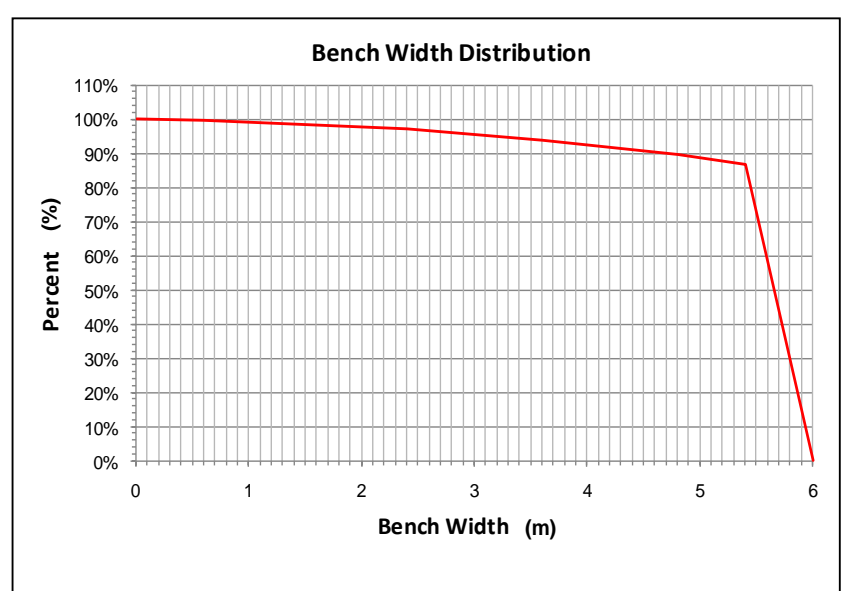

(b)

Figure 9 (a) Output of SBlock program showing the probability of failure expressed as a depth of failure of a bench applied to the southeast sector of Carmen de Andacollo final pit; (b) cumulative distribution of bench widths for the southeast sector of Carmen de Andacollo final pit

\subsection{Cuajone pit (SPCC)}

The Cuajone porphyry copper deposit is located on the western slopes of Cordillera Occidental, the southern Andes of Peru. The current pit measures about $2.5 \mathrm{~km}$ east-west, $3 \mathrm{~km}$ north-south, and at the end of 2012, had a maximum depth of $900 \mathrm{~m}$. Mining by open pit methods commenced in 1976 and has continued since that time. Ore production is $80 \mathrm{ktpd}$.

According to the geotechnical information provided from surface mapping and logging of several campaigns in the past, in the Cuajone pit nine structural domains had been defined (SRK Consulting (Chile) S.A., 2012). Table 2 summaries the structural parameters for the West sector.

Table 2 Structural data for West Sector (Domain A)

\begin{tabular}{ccccccccc}
\hline \multirow{2}{*}{ Set } & \multirow{2}{*}{ Dip } & DipDir & \multicolumn{3}{c}{ Spacing $(\mathrm{m})$} & \multicolumn{3}{c}{ Persistence $(\mathrm{m})$} \\
& & & Mean & Min & Max & Mean & Min & Max \\
\hline Joint 1 & $82^{\circ} \pm 15^{\circ}$ & $159^{\circ} \pm 15^{\circ}$ & 7 & 3 & 11 & 30 & 15 & 45 \\
Joint 2 & $88^{\circ} \pm 15^{\circ}$ & $097^{\circ} \pm 15^{\circ}$ & 7 & 3 & 11 & 30 & 15 & 45 \\
Joint 3 & $83^{\circ} \pm 15^{\circ}$ & $279^{\circ} \pm 15^{\circ}$ & 7 & 3 & 11 & 30 & 15 & 45 \\
Joint 4 & $44^{\circ} \pm 15^{\circ}$ & $226^{\circ} \pm 15^{\circ}$ & 7 & 3 & 11 & 30 & 15 & 45 \\
Joint 5 & $44^{\circ} \pm 15^{\circ}$ & $271^{\circ} \pm 15^{\circ}$ & 7 & 3 & 11 & 30 & 15 & 45 \\
Joint 6 & $842^{\circ} \pm 15^{\circ}$ & $189^{\circ} \pm 15^{\circ}$ & 3 & 1 & 5 & 15 & 7 & 23 \\
\hline
\end{tabular}

Notes:

Bench face dip $=67^{\circ}$; bench face dip direction $=180^{\circ}$; bench height $=15 \mathrm{~m}$; bench berm width $=9 \mathrm{~m}$.

Friction angle $=25^{\circ}$ and cohesion $=0$, for all joints/planes (discontinuities).

A calibration onsite was carried out using values shown in Table 2 for the different slope orientations in the structural domain A. A 3D plot of the benches indicates the location of failures identified by the program (Figure 10). This output from the program shows a good visual correlation with the observed frequency and type of failure observed in the pit benches. The failure volume and bench widths predicted by the SBlock outputs agree sufficiently with the observed instabilities of the slope benches. This initial study validated the adequacy of the methodology and further bench stability will be evaluated using the SBlock approach. Shear strength properties of faults/joints agreed with back-analyses and direct shear tests. 

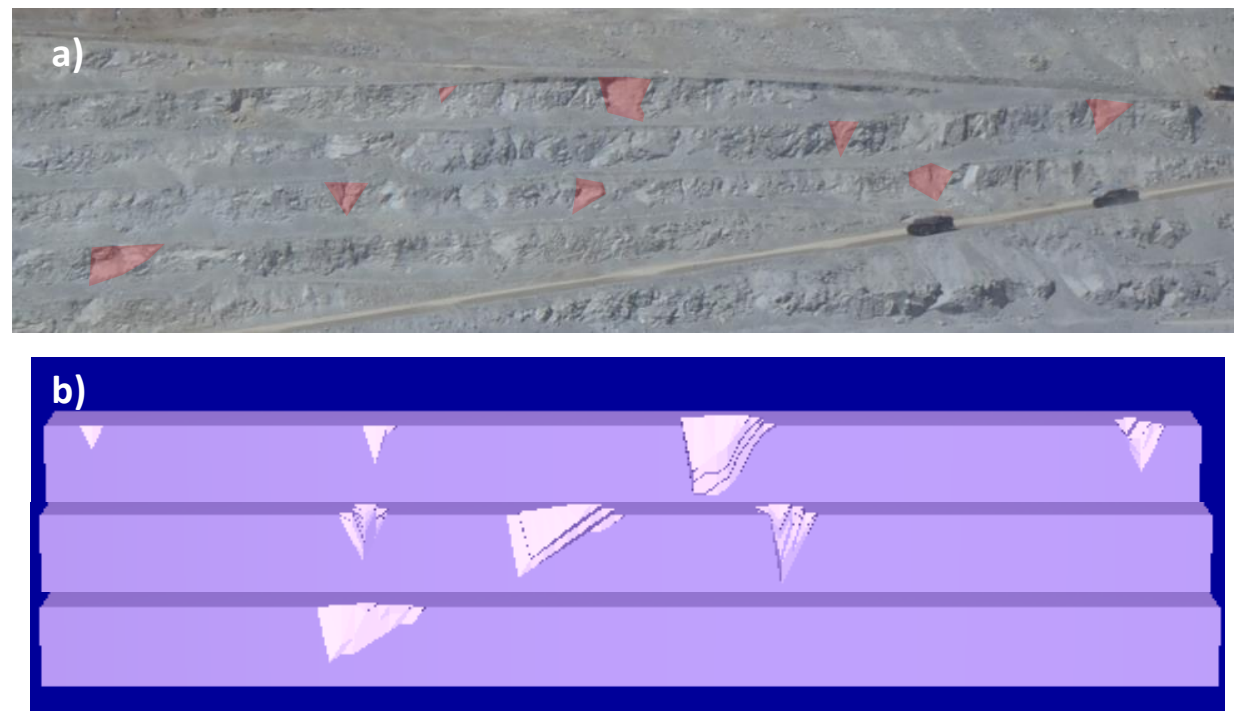

Figure 10 Calibration onsite of bench berm analysis; (a) sketch of the slopes benches in the West wall, structural domain A; (b) output of SBlock program showing the failed block removed (red zones) for this sector using structural domain data shown in Table 2

\section{$4 \quad$ Conclusions}

Owing to the large number of discontinuities exposed daily in producing open pit mines, a probabilistic approach to evaluating the potential for blocks/wedges to fail is required. A computer program which uses joints orientation, persistence and spacing statistics was implemented to develop a probabilistic approach which allows rapid determination of the probability of failure of blocks/wedges for different benches geometries.

The output of the program provides insight into the effective berm width, back-break, probability of failure and cumulative distribution of bench widths. The effect of increasing/decreasing the bench angle, increasing/decreasing the berm width and varying the slope orientation may be evaluated. Results of the application in two real cases presented in the paper show that the approach is able to provide useful results for practical mining situations and optimise interramp angles.

The methodology presented can help to answer these common types of questions in operating mines:

- By how much will the failure volume increase if we increase the bench face angle by $5^{\circ}$ ?

- By how much will the catch bench width be reduced because of crest failures?

- How will catch bench effectiveness be changed if we increase the interramp angle by $3^{\circ}$ ?

- How will the effective bench width change if I allow them to increase the single bench height to double bench height?

An improvement for the calibration process can be used by incorporating photogrammetry or laser scans of the slopes in order to compare back break widths and volumes.

\section{Acknowledgement}

The author thanks: Gabriel Esterhuizen, formerly of SRK Consulting, Denver for his support and review of this paper; TECK Carmen de Andacollo - Chile for permission and authorization to publish the paper; and especially Carmen de Andacollo, Mine Manager; Javier Escuti, and geotechnical team chief, Mauricio Tapia, who shared their mining experiences and practical knowledge in this project. The author also thanks the SPCC - Perú for permission and authorisation to publish the paper, and especially Cuajone Mine geotechnical superintendent, Raul Veramendi and geotechnical engineer, Jorge Barrios who were willing to share their mining experiences and practical knowledge in this project. 


\section{References}

Esterhuizen, G. (2004) SBLOCK v. 2.01, User Guide and Reference Manual, gester@icubed.com.

Dershowitz, W., Lee, G., Geier, J., Foxford, T., La Pointe, P. and Thomas, A. (1996) FracMan Interactive Discrete Feature Data Analysis, Geometric Modeling, and Exploration Simulation: User Documentation Version 2.5, Golder Associates Inc., Redmond, WA.

Goodman, R. and Shi, G.H. (1985) Block theory and its application to rock engineering, Prentice Hall, USA, 338 p.

Hormazabal, E., Tapia, M., Fuenzalida, R. and Zuñiga, G. (2011) Slope optimization for the Hypogene Project at Carmen de Andacollo pit, Chile, in Proceedings International Symposium on Rock Slope Stability in Open Pit Mining and Civil Engineering (Slope Stability 2011), E. Eberhardt and D. Stead (eds), 18-21 September 2011, Vancouver, Canada, Canadian Rock Mechanics Association, Canada, CD-rom only.

SRK Consulting (Chile) S.A. (2012) Estudio Geotécnico rajo Cuajone, Technical Report for SPCC, March (internal report). 